\title{
Магматические породы Гәрдвожского участка (Средний Тиман)
}

\author{
Куликова К.В., Шмакова А.М., Бурцев И.Н. \\ Институт геологии Коми НЦ УрО РАН, Сыктывкар, fopolina1@yandex.ru
}

\begin{abstract}
Аннотация. В статье впервые даётся геологическое, петрографическое и петрохимическое описание магматических пород Гэрдвожского участка, который был вскрыт в северо-восточном борту Четласского Камня Среднего Тимана в 2013г. В пределах участка обнажается тело (крупный ксенолит) габбро в окружении вулканических пород (базальтов и туфов) позднедевонского возраста. Установлено, что петрохимические характеристики базальтов соответствуют базальтам и долеритам трапповой формации позднедевонского возраста Тимана, а литовитрокластические туфы основного состава - формации щелочных вулканитов Тимана. Габбро участка Гердвож являются субщелочными породами, характеризующимися отличными от известных магматических пород палеозойского возраста Тимана петрохимическими особенностями. По петрографии и петрохимии габбро соответствует субщелочным габброидам Северного Тимана позднерифейского возраста.

Ключевые слова: Средний Тиман, субщелочное габбро, базальты, туфы.
\end{abstract}

\section{Igneous rocks of the Gerdvozh site (Middle Timan)}

\author{
Kulikova K.V., Shmakova A.M., Burtsev I.N. \\ Institute of the geology Komi SC UB RAS, Syktyvkar, fopolina1@yandex.ru
}

\begin{abstract}
A geological, petrographic and petrochemical description of igneous rocks of the Girdvozhsky site, which was discovered on the northeast side of the Chetlas Stone of the Middle Timan in 2013, is given for the first time. The gabbro body (large xenolith) on the territory of the Gerdvozh site is surrounded by volcanic rocks (basalts and tuffs) of the late Devonian age. It has been established that the petrochemical characteristics of basalts correspond to basalts and dolerites of the trap formation of the Late Devonian age of Timan, and the lithovitroclastic tuffs of basic composition correspond to the formations of alkaline Timan volcanites. The gabbro of the Gerdvozh site are represented by subalkaline rocks and differ from the well-known igneous rocks of the Paleozoic age of Timan by petrochemical features. In terms of petrography and petrochemistry, gabbro corresponds to the sub-alkaline gabbroids of the Northern Timan of the late Riphean age.
\end{abstract}

Keywords: Middle Timan, subalkaline gabbro, basalts, tuffs.

На Тиманском кряже широко развиты магматические породы двух формаций позднедевонского возраста: трапповой - покровы базальтов (валсовская свита $\left(\mathrm{D}_{3} \mathrm{vl}\right)$ ), а также силлы базальтов и дайки долеритов канино-тиманского комплекса $\left(\beta_{3}\right)$; формации щелочных вулканитов - стратифицированные толщи щелочных базальтов и их туфов (также выделяются в составе валсовской свиты (D,vl)) (Макеев, 2008; Тиманский кряж...,2010; Панева и др., 2016 ).

В 2013 г. при экспедиционных работах на Среднем Тимане в северо-восточном борту Четласского Камня (междуречье рек Ворыква и Щугор, восточная окраина нежилого поселка Тиман) была вскрыта толща вулканических пород валсовской свиты (базальты и туфы), а также тело интрузивных пород основного состава. Данный участок был назван Гэрдвожским (по названию протекающего рядом ручья). Поскольку на участке не наблюдается непосредственных контактов вулканической толщи и интрузивного тела, то геологический возраст последнего определить затруднительно. Поэтому первоначальной задачей стала типизация магматических пород Гэрдвожского участка для корреляции их с известными магматическими комплексами на Тимане.

Гэрдвожский участок имеет субизометричную форму диаметром 300 м. Интрузивное тело, оконтуренное по элювиальным высыпкам, локализовано в центральной части участка, имеет форму овала (280x110 м), простирается на северо-восток, коренные выходы обнажаются на южном (стенка около метра высотой) и северном окончаниях тела, на последнем породы подвержены тектоническим деформациям и, вероятно, претерпели гипергенные изменения. Вокруг интрузивного тела наблюдаются элювиальные высыпки базальтов, лишь в северной части участка наблюдается несколько разрозненных коренных выходов размером 0.5 м $\times 0.2$ м, породы в коренных выходах 
имеют субгоризонтальное залегание. Также в северной части виден контакт (был вскрыт расчисткой) базальтов и залегающих на них туфов.

Интрузивное тело сложено габбро. Порода имеют темно серый цвет и отчетливую шаровую текстуру. Размер шаров варьирует от 0.7 до 30 см, причем крупные шары сложены более мелкими, придавая породе на свежих сколах пятнистый облик. Шары имеют лейкократовый более крупнозернистый облик по сравнению с мелонакратовой мелкозернистой матрицей. При петрографическом описании под микроскопом установлено, что габбро характеризуется порфировидной структурой с габброофитовой основной массой. Породообразующие минералы представлены плагиоклазом (от 45 до $48 \%$ ): в центрах - лабрадором $\left(\mathrm{An}_{52-68}\right)$ и битовнитом $\left(\mathrm{An}_{78}\right)$, в каймах - олигоклазом $\left(\mathrm{An}_{27}\right)$, андезином $\left(\mathrm{An}_{35}\right)$ и лабрадором $\left(\mathrm{An}_{54}\right)$. Также установлены моноклинные пироксены $(10-28 \%)$, их химические составы соответствуют авгиту и субкальциевому авгиту, в меньшем количестве (5-10 \%) присутствует ромбический пироксен - гиперстен. КПШ (5 \%) формирует как мелкие собственные зерна до 50 мкм с содержанием ортоклазовго минала 80-85 \%, так и каймы вокруг плагиоклаза, где ортоклазовый минал не превышает 51 \%. Из рудных характерен титаномагнетит (5-7 \%), образующий как идиоморфные, так и ксеноморфные зерна размером от 60 мкм до 1 мм. Из акцессорных минералов наблюдаются иглы апатита. Из вторичных минералов в породе развиты пумпеллеит, пренит, глинистые фазы и цеолиты.

Базальты, окружающиегаббровое тело, это мелко-тонко зернистые светло-серого цвета породы. Структура в основном порфировая, гломеропорфировая с микролитовой основной массой, текстура микроминдалекаменная. Плагиоклаз первой генерации (20-25 \%) образует разноориентированные призматические, длиннопризматические, реже таблитчатые и размером 0.5-1.5мм, фенокристаллы, нередко образующие скопления и сростки. По составу отвечает лабрадору (An 60-65). Клинопироксен первой генерации (5-10 \%), слагает субпризматические и длиннопризматические (0.3-1.2 мм) зерна, присутствует в скоплениях и сростках. Плагиоклаз и клинопироксен второй генерации (0.1-0.5 мм) с рудным минералом, палагонитом и вулканическим стеклом выполняют основную мелкозернистую неполнокристаллическую массу породы, составляющую 70 \%. Микроминдалены заполнены хлоритом.

Литовитрокластические туфы, залегающие на базальтах, имеют цвета от сургучного до фиолетового, характеризуются обломочной текстурой и псаммитовой структурой. Литокласты представлены обломками песчаников и базальтов, наиболее многочисленными являются витрокласты.

Был изучен химический состав пород Гэрдвожского участка (см. таблицу) и с целью типизации проведено сравнение полученных петрохимических характеристик с таковыми в базальтах и долеритах трапповой формации Среднего Тимана (Анферова, Удоратина, 2013; Удоратина и др., 2014), в щелочных базальтах и их туфах из керна скважин Верхне-Щугорского месторождения Среднего Тимана (Панева и др., 2016), в позднерифейских субщелочных габброидах мыса Румяничный Северного Тимана (Костюхин, Степаненко, 1987; Андреичев, 1998).

Габбро Гэрдвожского участка $\left(\mathrm{SiO}_{2} 47.29-51.29\right.$ мас. \%, $\left(\mathrm{Na}_{2} \mathrm{O}+\mathrm{K}_{2} \mathrm{O}\right) 2.26-5.15$ мас. \%) относятся к основным породам и, также как и субщелочные габбро Северного Тимана, принадлежат к семействам габбро и монцогаббро. Данные породы относятся к субщелочному петрохимическому ряду, характеризуются умеренно калиевым и калиевым типом щелочности.

Базальты Гэрдвожского участка $\left(\mathrm{SiO}_{2} 48.50-52.90\right.$ мас. \%, $\left(\mathrm{Na}_{2} \mathrm{O}+\mathrm{K}_{2} \mathrm{O}\right) 2.63-4.14$ мас. \%) относятся к основным породам и принадлежат к семействам базальтов и основных пикробазальтов. Они принадлежат к нормально-щелочному петрохимическому ряду, характеризуются низко калиевым и умеренно калиевым типом щелочности. По этим характеристикам они соответствуют базальтам и долеритам трапповой формации Тимана позднедевонского возраста.

Туфы Гэрдвожского участка $\left(\mathrm{SiO}_{2} 47,28\right.$ - 62,99 мас. \%, $\left(\mathrm{Na}_{2} \mathrm{O}+\mathrm{K}_{2} \mathrm{O}\right) 6,14-7,02$ мас. \%) относятся к основным и средним породам и принадлежат к семейству щелочных базальтов и рахиандезитов, относятся к щелочному ряду и характеризуются высококалиевым типом щелочности. Этим они сопоставимы с породами палеозойской формации щелочных вулканитов Среднего Тимана 


\begin{tabular}{|c|c|c|c|c|c|c|c|c|c|c|c|c|c|c|c|c|}
\hline I & $\stackrel{m}{I}$ & $\frac{\infty}{\vec{b}}$ & $\stackrel{g}{\circ}$ & 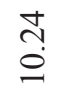 & ָे & $\begin{array}{l}\infty \\
\stackrel{\infty}{0} \\
0\end{array}$ & $\begin{array}{l}\infty \\
\stackrel{\infty}{0} \\
\stackrel{0}{\circ}\end{array}$ & $\underset{i n}{ \pm}$ & ñ? & ñ? & ठे. & $\exists$ & $\underset{+}{\stackrel{+}{+}}$ & $\hat{a}$ & $\overrightarrow{0}$ & ลें \\
\hline 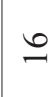 & 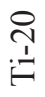 & $\begin{array}{l}\stackrel{\infty}{\sim} \\
\underset{\forall}{\sim}\end{array}$ & $\stackrel{m}{\dddot{m}}$ & $\begin{array}{l}\dot{J} \\
\dot{g}\end{array}$ & $\begin{array}{l}\Xi \\
\beth\end{array}$ & $\stackrel{\infty}{\infty}$ & $\begin{array}{l}n \\
0 \\
0\end{array}$ & $\begin{array}{l}\stackrel{0}{0} \\
\stackrel{0}{ }\end{array}$ & $\stackrel{\text { oे }}{.}$ & $\tilde{n}$ & $\begin{array}{l}\text { 6్ } \\
\text { in }\end{array}$ & $=$ & $\hat{a}$ & $\begin{array}{l}\hat{\sigma} \\
\stackrel{i}{i}\end{array}$ & $\overrightarrow{\widetilde{o}}$ & ָे \\
\hline
\end{tabular}

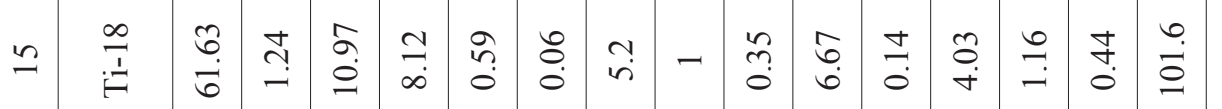

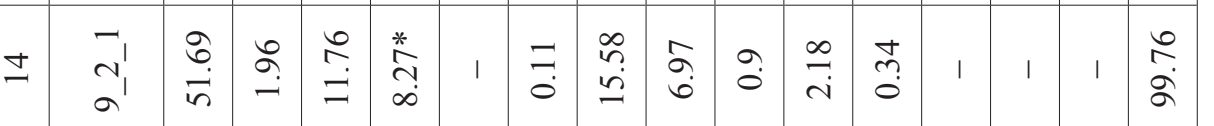

\begin{tabular}{|c|c|c|c|c|c|c|c|c|c|c|c|c|c|c|c|c|}
\hline$\cong$ & త্ర & $\underset{\dot{\infty}}{\stackrel{\rho}{+}}$ & $\stackrel{\Xi}{\sim}$ & $\underset{\vec{J}}{\stackrel{\vec{\sigma}}{\beth}}$ & 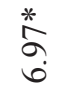 & I & $\overrightarrow{0}$ & 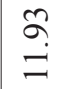 & $\stackrel{ }{0}$ & $\stackrel{\overbrace{}}{\sim}$ & $\stackrel{+}{o}$ & $\vec{\jmath}$ & 1 & 1 & 1 & ̊̊ \\
\hline
\end{tabular}

क

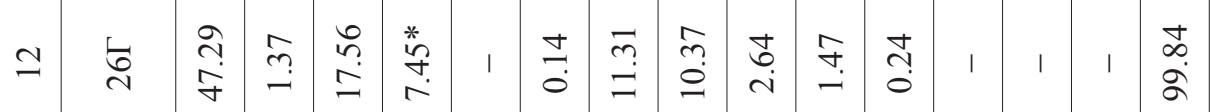

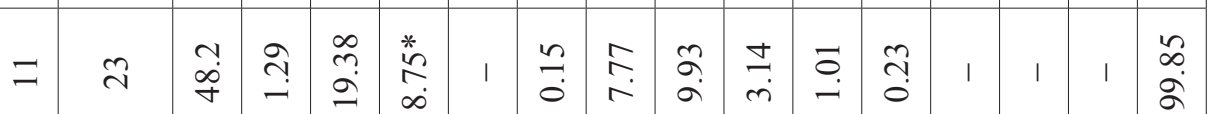

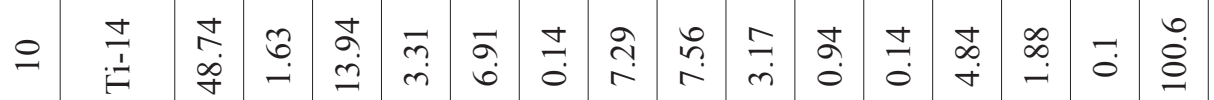

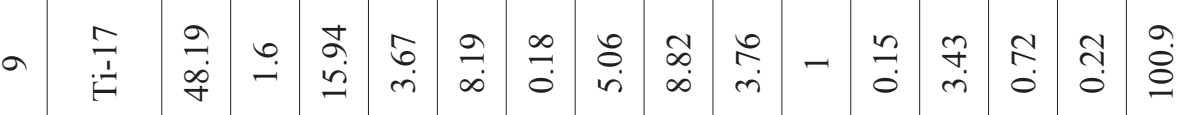

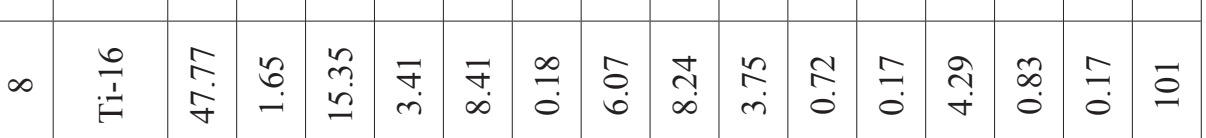

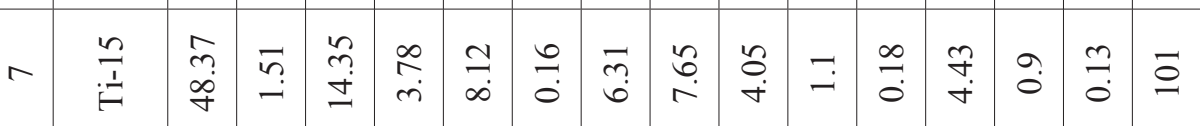

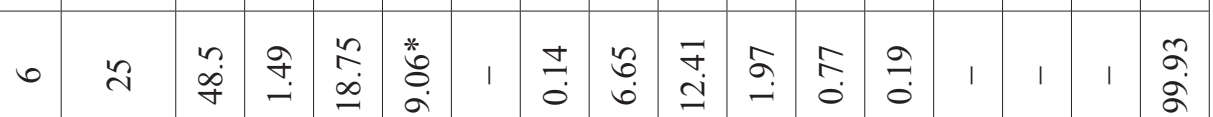

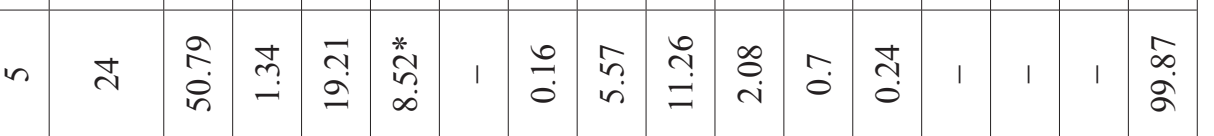

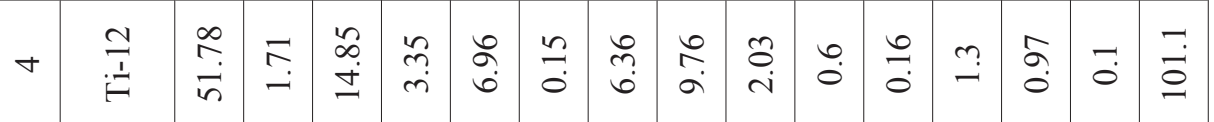

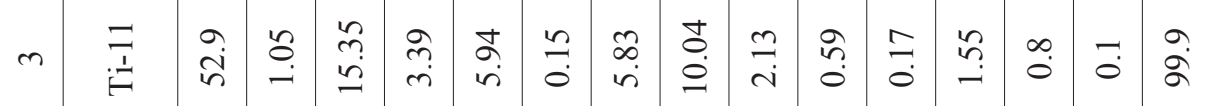

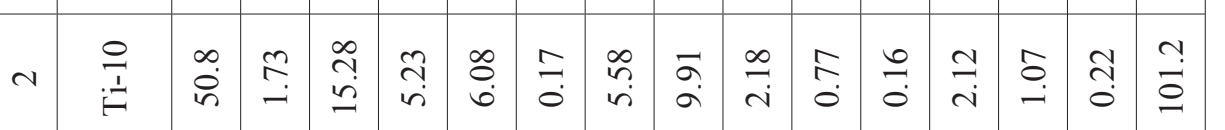

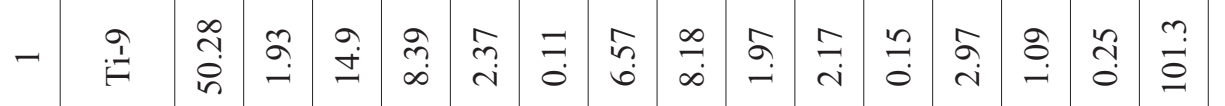

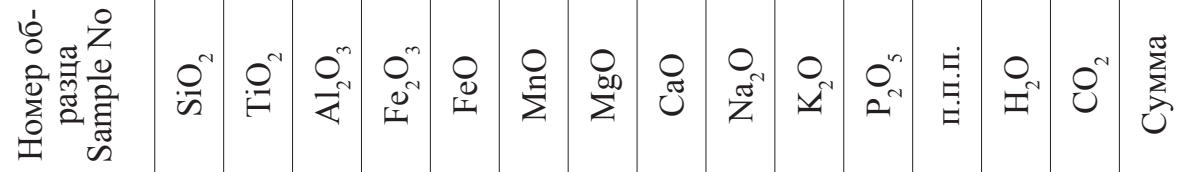


Составы габбро Гэрдвожского участка, также как и составы субщелочного габбро Северного Тимана, относятся к известково-щелочной серии пород. Для базальтов Гэрдвожского участка характерен толеитовый тренд, типичный и для пород трапповой формации. Туфы Гэрдвожского участка относятся к щелочной серии.

Для интерпретации особенностей исследуемых пород составы были пересчитаны по методу CIPW. B нормативном составе пород Гэрдвожского участка выявлены различия. Габбро содержат в нормативном составе оливин (10-12 \%) и в незначительном количестве нефелин (0.5-2\%), то есть они являются кремнезем недосыщенными породами. По этому параметру они соответствуют позднерифейским субщелочным габбро мыса Румяничный Северного Тимана. Для базальтов характерны нормативные кварц и гиперстен, следовательно они являются кремнезем пересыщенными породами и по этим характеристикам однотипны с базальтами и долеритами позднедевонской трапповой формации Тимана.

Таким образом впервые изучены магматические породы, вскрытые в пределах палеозойских отложений (валсовская свита $\left.\left(\mathrm{D}_{3} \mathrm{vl}\right)\right)$ на Среднем Тимане на восточном окончании поселения Тиман. Их выходы названы как Гэрдвожский участок. Среди пород участка выявлены габбро, базальты и литовитрокластические туфы. Установлено, что петрохимические характеристики базальтов соответствуют базальтам и долеритам трапповой формации позднедевонского возраста Тимана, а литовитрокластические туфы основного и среднего состава - палеозойской формации щелочных вулканитов Тимана. Габбро участка Гердвож являются субщелочными породами, характеризующимися отличными от известных магматических пород палеозойского возраста Тимана петрохимическими особенностями. По петрографии и петрохимии габбро соответствует субщелочным габброидам Северного Тимана позднерифейского возраста. Таким образом габбро участка Гэрдвож можно считать чужеродным по отношению к палеозойским магматическим породам Тимана, а тело, которое они образуют, считать крупным ксенолитом в пределах базальтовой толщи.

Работа выполнена в рамках темы НИР ГР № АААА-А17-117121270035-0.

\section{Литература}

1. Андреичев В.Л. Изотопная геохронология интрузивного магматизма Северного Тимана. Екатеринбург: УрО РАН. 1998. $90 \mathrm{c}$.

2. Анферова Е.А., Удоратина О.В. Базальты Верхне-Ворыквинского покрова Среднего Тимана // Структура, вещество, история литосферы Тимано-Североуральского сегмента. Мат-лы 22-й научной конференции. Сыктывкар. Геопринт. 2013. С. 8-12.

3. Костюхин М.Н., Степаненко В.И. Байкальский магматизм Канино-Тиманского региона. Л. Изд-во: Наука. $1987.232 \mathrm{c}$.

4. Макеев А.Б, Лебедев В.А., Брянчанинова Н.И. Магматиты Среднего Тимана. Екатеринбург: УрО РАН. 2008. 348 c. ISBN 5-7691-1878-4.

5. Панева А.А., Куликова К.В., Бурцев И.Н. Внутриплитный палеозойский магматизм Среднего Тимана // Петрология магматических и метаморфических комплексов. 2016. № 8. С. 266-273.

6. Тиманский кряж [Текст]. В 2 т. Т. 2. Литология и стратиграфия, геофизическая характеристика Земной коры, тектоника, минерально-сырьевые ресурсы: монография. Ухта: УГТУ. 2010. 437 с. ISBN 978-5-88179-519-1.

7. Удоратина О.В., Андреичев В.Л., Саватенков В.М. и др. Геология и минеральные ресурсы Европейского Северо-Востока России // Материалы XVI Геологического съезда Республики Коми. T. II. Сыктывкар. ИГ Коми НЦ УрО РАН. 2014. С. 128-131. 